\title{
CORRECTION
}

\section{Correction to: Identities behind some congruences for r-Bell and derangement polynomials}

Grzegorz Serafin (1)

\section{${ }^{*}$ Correspondence:}

grzegorz.serafin@pwr.edu.pl

Faculty of Pure and Applied

Mathematics, Wrocław University

of Science and Technology, UI.

Wybrzeże Wyspiańskiego 27,

Wrocław, Poland

\section{Correction to: G. Serafin Res. Number Theory (2020) 6:39 https://doi.org/10.1007/s40993-020-00216-y}

In the original article there were capitalization errors in two of the references. The corrected references follow:

The original article can be found online at https://doi.org/10.1007/s40993-020-00216-y.

Published online: 19 October 2020

References

16. $\mathrm{Mu}, \mathrm{Q}$ : A new proof of the Sun-Zagier congruence. Nanjing Univ. J. Math. Biquarterly 35(1), 39-43 (2018)

18. Sun, Z.W.: A new extension of the Sun-Zagier result involving Bell numbers and derangement numbers. arxiv:2006.16089 (2020)

Publisher's Note

Springer Nature remains neutral with regard to jurisdictional claims in published maps and institutional affiliations. 